Article

\title{
Synthesis of Shape-Tailored $\mathrm{WO}_{3}$ Micro-/Nanocrystals and the Photocatalytic Activity of $\mathrm{WO}_{3} / \mathrm{TiO}_{2}$ Composites
}

\author{
István Székely ${ }^{1,+}$, Gábor Kovács ${ }^{2,3,4,+}$, Lucian Baia ${ }^{2,4}$, Virginia Danciu ${ }^{1}$ and Zsolt Pap ${ }^{2,3,4,5, *, \dagger}$ \\ 1 Faculty of Chemistry and Chemical Engineering, Babeș-Bolyai University, Arany János 11, \\ Cluj-Napoca RO-400028, Romania; szistike@yahoo.com (I.S.); vdanciu@chem.ubbcluj.ro (V.D.) \\ 2 Faculty of Physics, Babeș-Bolyai University, M. Kogălniceanu 1, Cluj-Napoca RO-400084, Romania; \\ gkovacs@chem.ubbcluj.ro (G.K.); lucian.baia@phys.ubbcluj.ro (L.B.) \\ 3 Department of Applied and Environmental Chemistry, University of Szeged, Rerrich Béla tér 1, \\ Szeged HU-6720, Hungary \\ 4 Institute for Interdisciplinary Research on Bio-Nano-Sciences, Treboniu Laurian 42, \\ Cluj-Napoca RO-400271, Romania \\ 5 Institute of Environmental Science and Technology, Tisza Lajos krt. 103, Szeged HU-6720, Hungary \\ * Correspondence: pap.zsolt@phys.ubbcluj.ro or pzsolt@chem.u-szeged.hu; \\ Tel.: +40-264-593833 or $+36-62-544338$ \\ + These authors contributed equally to this work.
}

Academic Editor: Klára Hernádi

Received: 10 February 2016; Accepted: 24 March 2016; Published: 31 March 2016

\begin{abstract}
A traditional semiconductor $\left(\mathrm{WO}_{3}\right)$ was synthesized from different precursors via hydrothermal crystallization targeting the achievement of three different crystal shapes (nanoplates, nanorods and nanostars). The obtained $\mathrm{WO}_{3}$ microcrystals were analyzed by the means of X-ray diffraction (XRD), scanning electron microscopy (SEM) and diffuse reflectance spectroscopy (DRS). These methods contributed to the detailed analysis of the crystal morphology and structural features. The synthesized bare $\mathrm{WO}_{3}$ photocatalysts were totally inactive, while the $\mathrm{P} 25 / \mathrm{WO}_{3}$ composites were efficient under UV light radiation. Furthermore, the maximum achieved activity was even higher than the bare P25's photocatalytic performance. A correlation was established between the shape of the $\mathrm{WO}_{3}$ crystallites and the observed photocatalytic activity registered during the degradation of different substrates by using $\mathrm{P} 25 / \mathrm{WO}_{3}$ composites.
\end{abstract}

Keywords: hydrothermal crystallization; $\mathrm{WO}_{3}$ nanocrystallites; $\mathrm{WO}_{3} / \mathrm{TiO}_{2}$ nanocomposites; photocatalytic activity; shape tuning/tailoring

\section{Introduction}

$\mathrm{WO}_{3}$ is a well-known semiconductor with a large applicability spectrum. Its color can vary from yellow, green, bluish and grayish depending on the oxidation state of the tungsten atoms in the crystal structure. It is a widely studied transition metal oxide with a light absorption maximum $\approx 480 \mathrm{~nm}$ (the band gap of $\mathrm{WO}_{3}$ is $\approx 2.6 \mathrm{eV}$ [1], yellowish color), stable under acidic and oxidative conditions and most importantly, it is considered harmless. Over the years, $\mathrm{WO}_{3}$ nanomaterials were applied as pigments for paints [2], gas-, humidity- and moisture sensors [3], important components of energy efficient (smart) windows, antiglare automobile rear-view mirrors and sunroofs [4]. $\mathrm{WO}_{3}$ is capable of electrochromism, which is an optical modulation between blue color and transparent, a feature that occurs upon ion-electron double injection and extraction [5].

$\mathrm{WO}_{3}$ nanocrystallites can be synthesized using various methods, the most common being the ones using hydrothermal crystallization. Tungsten trioxide shows four well-known crystal phases: 
tetragonal, orthorhombic, monoclinic and triclinic. The most frequently obtained crystal phase is monoclinic [6]. Tungsten trioxide has been widely studied as a potential photocatalyst, although the photoactivity of $\mathrm{WO}_{3}$ is relatively low (compared to $\mathrm{TiO}_{2}$ ) [7] and can be significantly enhanced if it is applied in composite systems with noble metals or other semiconductor oxides [8].

The main advantages of $\mathrm{WO}_{3}$ are that it can be synthesized relatively easy; it absorbs and reflects light (its color can vary from yellow, green to blue and white/grey) at a much broader spectral range compared to $\mathrm{TiO}_{2}$. The band-gap of $\mathrm{WO}_{3}$ is narrower compared to $\mathrm{TiO}_{2}$, which means that $\mathrm{WO}_{3}$ requires lower energy photons in the heterogeneous photocatalytic process [9].

The synthesis of $\mathrm{WO}_{3}$ semiconductors has received significant attention in the last few years. Most of these studies were focused on the morphology of $\mathrm{WO}_{3}$ obtained by hydrothermal crystallization, which is a frequently used preparation procedure. In some cases, it can behave also as a charge separator [10] meaning that this semiconductor can enhance other semiconductors' charge separation efficiency; therefore, it is a viable option for composite systems [11-13]. $\mathrm{WO}_{3}$ can form composites with noble metals such as $\mathrm{Pt}, \mathrm{Au}$ or with other semiconductors like $\mathrm{TiO}_{2}, \mathrm{ZnO}$ or even $\mathrm{NiO}$. The most widely used combinations are those with $\mathrm{TiO}_{2}$ and noble metals. The above listed composites were used as gas sensors [14,15] or as very efficient photocatalysts [16].

The morphology of $\mathrm{WO}_{3}$ can be influenced with the temperature of the hydrothermal crystallization, the precursors' structure and solvent's polarity, $\mathrm{pH}$, etc. [17-19]. Tungsten trioxide can be synthesized starting from a larger variety of precursors including: tungstic acid, sodium tungstate and ammonium metatungstate. These compounds were already proved to yield different crystal geometries of $\mathrm{WO}_{3}[1,20,21]$.

In this work, $\mathrm{WO}_{3}$ photocatalysts were obtained from three different precursors via hydrothermal crystallization. The morphology, structure and photocatalytic activity of $\mathrm{WO}_{3}$ were studied and $\mathrm{WO}_{3} / \mathrm{TiO}_{2}$ composites were prepared and their photoactivity was evaluated and the activity-morphology-structure relationship was established.

\section{Results}

\subsection{Photocatalytic Activity}

Data from the literature shows that $\mathrm{WO}_{3}$ photocatalysts' activity was usually very low, excepting some specific cases [18]. To verify this, the photocatalytic activity of the bare $\mathrm{WO}_{3}$ nanocrystals were tested both under UV and visible light. As Figures 1 and 2 shows, (only the degradation of phenol under visible light and of oxalic acid under UV light are shown) the synthesized semiconductors were not active compared to Evonik Aeroxide $\mathrm{P}_{2} 5 \mathrm{TiO}_{2}$ (later on, the commercial product will be denoted as P25), which was active also under both visible- and UV light. The visible light activity can be attributed to the presence of a small fraction of rutile crystal phase in P25 [22,23].

The inactivity of the $\mathrm{WO}_{3}$ nano- and microcrystals possibly resides in the following issues:

a.) large particle size of the synthesized $\mathrm{WO}_{3}$. Although the obtained microcrystals have hierarchical structure, their secondary morphology was in the micrometer range. It is already known in the case of titania that, over a certain particle size, the overall photocatalytic activity decreases (some of the largest titania crystals which are known to have good photocatalytic activity are Aldrich rutile and Aldrich anatase, each of them having a crystal size above $100 \mathrm{~nm}$ [24].

b.) the absence of an electron acceptor. In some cases, an electron acceptor (e.g., noble metal nanocrystals) can enhance the activity of a semiconductor [6], which was missing from our composite system (from the $\mathrm{WO}_{3}$ 's point of view).

As it can be seen, the bare $\mathrm{WO}_{3}$ crystallites are not active at all under UV/visible light. However, $\mathrm{WO}_{3}$ is known also for electrochromic properties, which are based on its electron acceptor capacity. This was exploited in composite systems in which $\mathrm{TiO}_{2}$ is in contact with $\mathrm{WO}_{3}$. The composites were obtained according to the Section 4.3. 
The best way to examine the influence of the chosen $\mathrm{WO}_{3} \mathrm{~s}$ on the photocatalytic activity of titania is to choose a very active, vastly documented photocatalyst. Therefore, the best option is P25. It is known to degrade the majority of organic contaminants (phenol, 4-chlorophenol, dichloroacetic acid, dimethylamine, trichloroethylene, acid orange 7, methylene blue, methanol, etc. [25]) and is considered the most unselective photocatalyst, producing lower amounts of intermediate compounds.

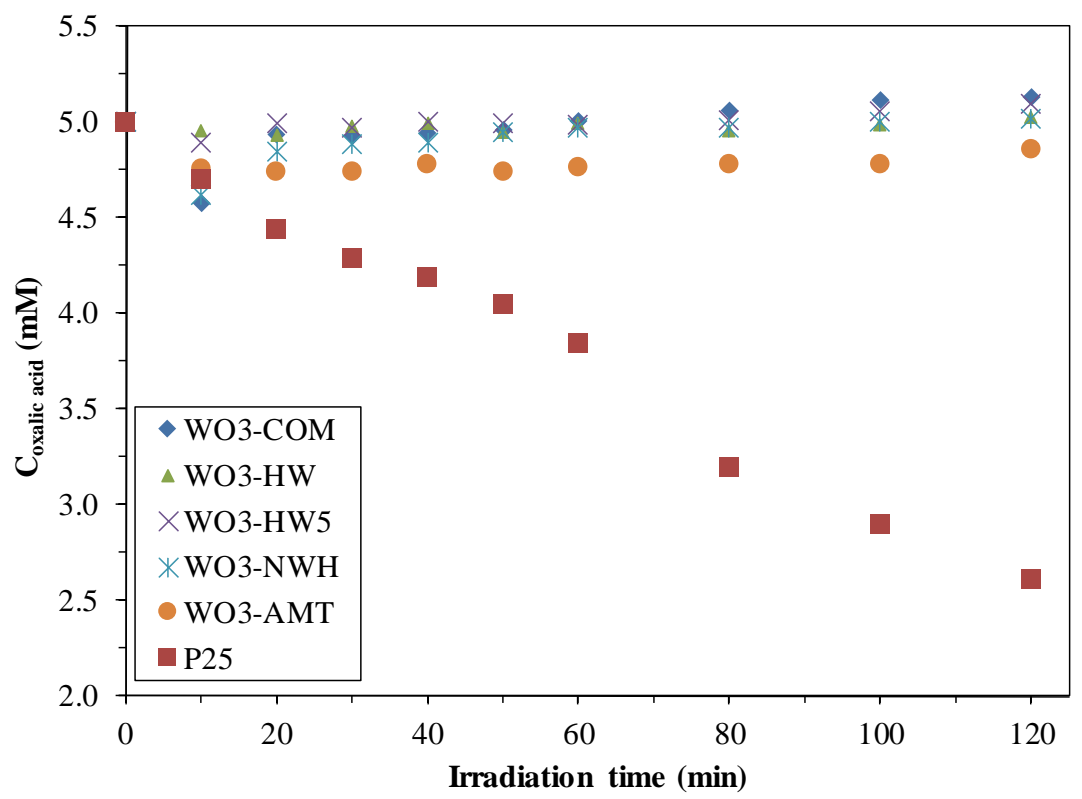

Figure 1. Photodegradation of oxalic acid under UV light using bare $\mathrm{WO}_{3}$.

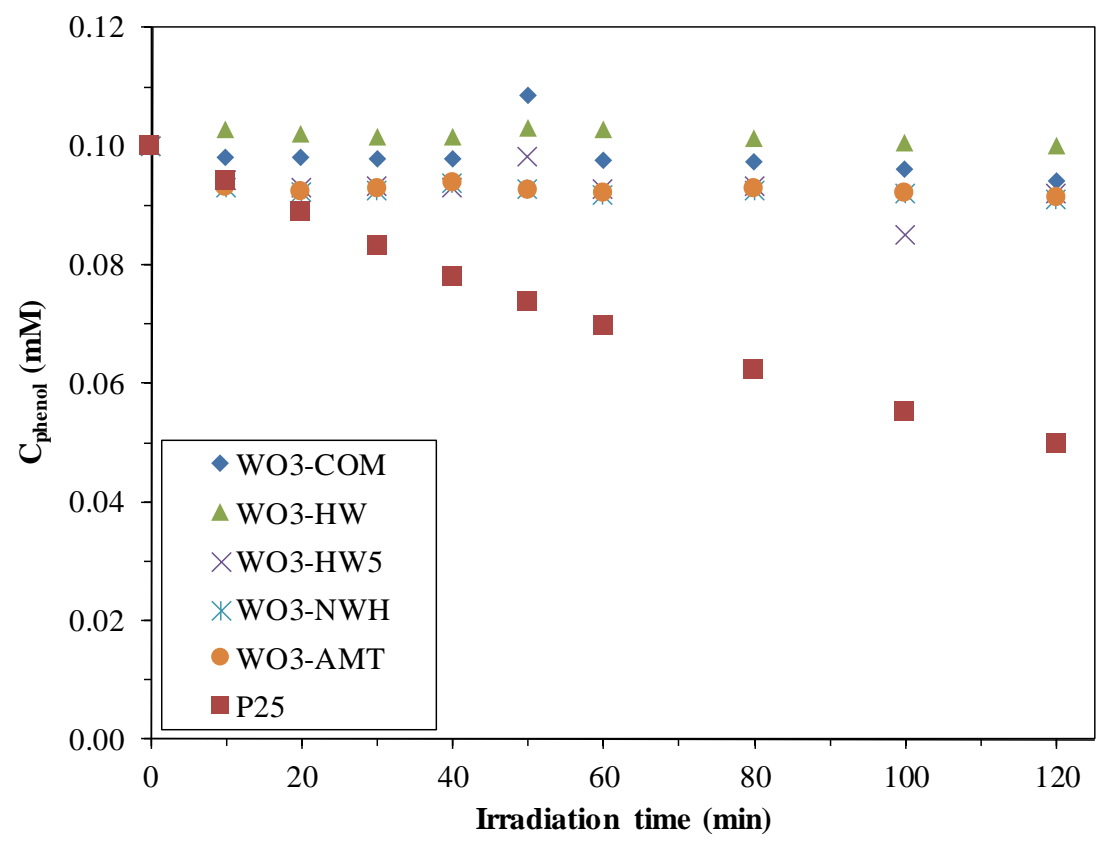

Figure 2. Photode gradation of phenol under visible light with $\mathrm{WO}_{3}$ microcrystallites.

\subsection{Phenol Conversion Rates}

After 1 h, P25 degraded 54.3\% of the total phenol concentration. From Figure 3, it can be observed that there were two types of composites (the short names for the obtained $\mathrm{WO}_{3} \mathrm{~s}$ can be found in the experimental section). Some of their efficiency was lower than the efficiency of P25: 
$\mathrm{WO}_{3}-\mathrm{NWH}+\mathrm{P} 25$ (27.5\% degraded phenol), $\mathrm{WO}_{3}-\mathrm{COM}+\mathrm{P} 25$ (25.4\% degraded phenol), $\mathrm{WO}_{3}-\mathrm{AMT}$ + P25 (33.4\% degraded phenol) and $\mathrm{WO}_{3}-\mathrm{HW} 5+\mathrm{P} 25$ (45.3\% degraded phenol). $\mathrm{WO}_{3}-\mathrm{HW}+\mathrm{P} 25$ was the only composite with slightly superior activity compared to P25, showing a $63.9 \%$ phenol decomposition efficiency. According to other published data, this result is interesting, as the $\mathrm{WO}_{3}-\mathrm{TiO}_{2}$ composites' efficiency towards phenol was reported to be lower [6] compared to that of the bare $\mathrm{TiO}_{2}$. Higher activity was achieved only when a third composite component (noble metals- $\mathrm{Au}$ or $\mathrm{Pt}$ ) was also introduced or the $\mathrm{TiO}_{2}-\mathrm{WO}_{3}$ interparticle contact was maximized by the adjustment of the semiconductors' surface charge $[16,26,27]$. The main reason for which the degradation curves were plotted separately after $1 \mathrm{~h}$ and $2 \mathrm{~h}$ was that, after one hour, the degradation rates were not influenced significantly by the intermediates' concentration.

After $2 \mathrm{~h}$, the reference photocatalyst degraded $86.8 \%$ of the organic pollutant. $\mathrm{WO}_{3}-\mathrm{NWH}+$ P25 (44.4\% degraded phenol), $\mathrm{WO}_{3}-\mathrm{COM}+\mathrm{P} 25$ (49.1\% degraded phenol), $\mathrm{WO}_{3}-\mathrm{AMT}+\mathrm{P} 25$ (58.7\% degraded phenol), and $\mathrm{WO}_{3}-\mathrm{HW} 5+\mathrm{P} 25$ composite (66.7\% degraded phenol) remained less photoactive than $\mathrm{P} 25 . \mathrm{WO}_{3}-\mathrm{HW}+\mathrm{P} 25$ was the only composite that showed a comparable efficiency towards phenol degradation, achieving $87.2 \%$ degradation. The degradation efficiency values of $\mathrm{P} 25$ and $\mathrm{WO}_{3}-\mathrm{HW}+$ P25 were much closer after $2 \mathrm{~h}$ ( $1 \mathrm{~h}$ of degradation: $54.3 \%$ vs. $63.9 \% ; 2 \mathrm{~h}$ of degradation: $86.8 \%$ vs. $87.2 \%$ ).
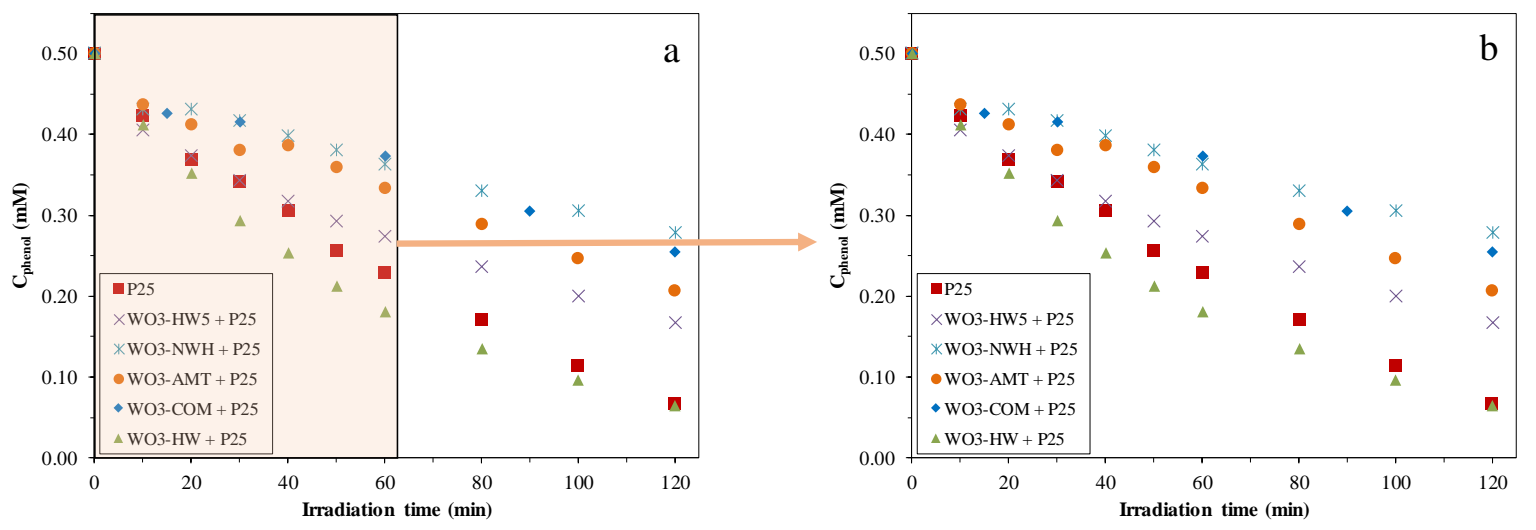

Figure 3. Degradation curves of phenol using $\mathrm{WO}_{3}-\mathrm{P} 25$ composites under UV light, after $2 \mathrm{~h}(\mathbf{a})$; and $1 \mathrm{~h}(\mathbf{b})$.

\subsection{Reaction Rates of the Phenol Degradation}

The reference photocatalyst showed $8.90 \times 10^{-3} \mathrm{mmol} \cdot \mathrm{dm}^{-3} \cdot \mathrm{min}^{-1}$ initial reaction rate, which was inferior compared to $\mathrm{WO}_{3}-\mathrm{COM}+\mathrm{P} 25-11.18 \times 10^{-3} \mathrm{mmol} \cdot \mathrm{dm}^{-3} \cdot \mathrm{min}^{-1}$. Interestingly, the initial reaction rate of $\mathrm{WO}_{3}-\mathrm{HW}+\mathrm{P} 25$ composite was nearly identical with the value shown by $\mathrm{P} 25-8.86 \times 10^{-3} \mathrm{mmol} \cdot \mathrm{dm}^{-3} \cdot \mathrm{min}^{-1}$. Although the $\mathrm{WO}_{3}-\mathrm{COM}+\mathrm{P} 25$ showed the highest initial reaction rate, after $2 \mathrm{~h}$ it degraded only $50 \%$ of the phenol, while $\mathrm{WO}_{3}-\mathrm{HW}+\mathrm{P} 25$ removed $87.2 \%$. The reaction rates of the other composites were noticeably lower than the value obtained for P25. The differences and inconsistencies shown between the degradation yields and initial reaction rates raised the following important aspect: the activity values of the composites were dependent from the chosen model pollutant-representative examples are methylene blue, rhodamine B, malachite green, 2-chloro-phenol, 2-nitro-phenol and phenol, which show an affinity at different levels towards $\mathrm{WO}_{3}$ [28-33].

Nevertheless, different substrates also mean different degradation pathways. It is remarkable that a pollutant with a relatively simple structure such as phenol itself degrades through different intermediates in different proportions when the same type of composite is applied (the difference in these cases is usually just the composite build-up). However, fortunately, there are common intermediates in the degradation pathways, such as hydrochinon, pyrocatechol and resorcinol $[34,35]$. 
The end products, of course, in each of these reactions are water and $\mathrm{CO}_{2}$. Hence, in order to get more information about the activity of these nanomaterials, another model pollutant is needed.

\subsection{Reaction of the Methyl-Orange Degradation}

From Figure 4, it was observed that the $\mathrm{WO}_{3}-\mathrm{P} 25$ composites showed different photocatalytic activities. The most important aspect was that, in the first hour of the photodegradation tests, the $\mathrm{MO}$ concentration decreased linearly. After $2 \mathrm{~h}, \mathrm{WO}_{3}-\mathrm{NWH}+\mathrm{P} 25$ degraded $57.7 \%, \mathrm{WO}_{3}-\mathrm{COM}+$ $\mathrm{P} 25-59.5 \%, \mathrm{WO}_{3}-\mathrm{HW}+\mathrm{P} 25-67.3 \%$ of the total MO. The two best performing nanocomposites were $\mathrm{WO}_{3}-\mathrm{HW} 5+\mathrm{P} 25$ (76.3\% degraded MO) and $\mathrm{WO}_{3}-\mathrm{AMT}+\mathrm{P} 25$ (84.6\% degraded MO), while P25 removed $82.8 \%$ of the $\mathrm{MO}$ (Table 1 ).

The highest reaction rate was shown by $\mathrm{WO}_{3}-\mathrm{COM}+\mathrm{P} 25\left(5.02 \mathrm{mmol} \cdot \mathrm{dm}^{-3} \cdot \mathrm{min}^{-1}\right)$ and the lowest by $\mathrm{WO}_{3}-\mathrm{NWH}+\mathrm{P} 25\left(0.35 \mathrm{mmol} \cdot \mathrm{dm}^{-3} \cdot \mathrm{min}^{-1}\right)$. Although there was a significant difference between the two reaction rates, they only degraded $\approx 60 \%$ of $\mathrm{MO}$, emphasizing again the importance of the degradation pathway of a given model pollutant. Similar incoherence was observed when comparing $\mathrm{WO}_{3}$-AMT + P25 and P25 (84.6\% vs. 82.8\% MO degradation/ $1.66 \mathrm{mmol} \cdot \mathrm{dm}^{-3} \cdot \mathrm{min}^{-1}$, $\left.2.26 \mathrm{~mol} \cdot \mathrm{dm}^{-3} \cdot \mathrm{min}^{-1}\right)$. However, there are cases, when the obtained reaction rates and degradation yields showed a similar trend: $\mathrm{WO}_{3}-\mathrm{HW}+\mathrm{P} 25\left(1.01 \mathrm{mmol} \cdot \mathrm{dm}^{-3} \cdot \mathrm{min}^{-1}\right)$ vs. $\mathrm{WO}_{3}-\mathrm{HW} 5+\mathrm{P} 25$ $\left(1.06 \mathrm{~mol} \cdot \mathrm{dm}^{-3} \cdot \mathrm{min}^{-1}\right)$ and $67.3 \% \mathrm{MO}$ degradation $v \mathrm{~s} .76 .3 \% \mathrm{MO}$ degradation.

As it was shown in this section, based upon the photodegradation results, the following main question arises: If the base photocatalyst was the same in all of the cases (Evonik Aeroxide P25) and the composites' composition was also constant, which morpho-structural parameter was responsible for the different photocatalytic activity?

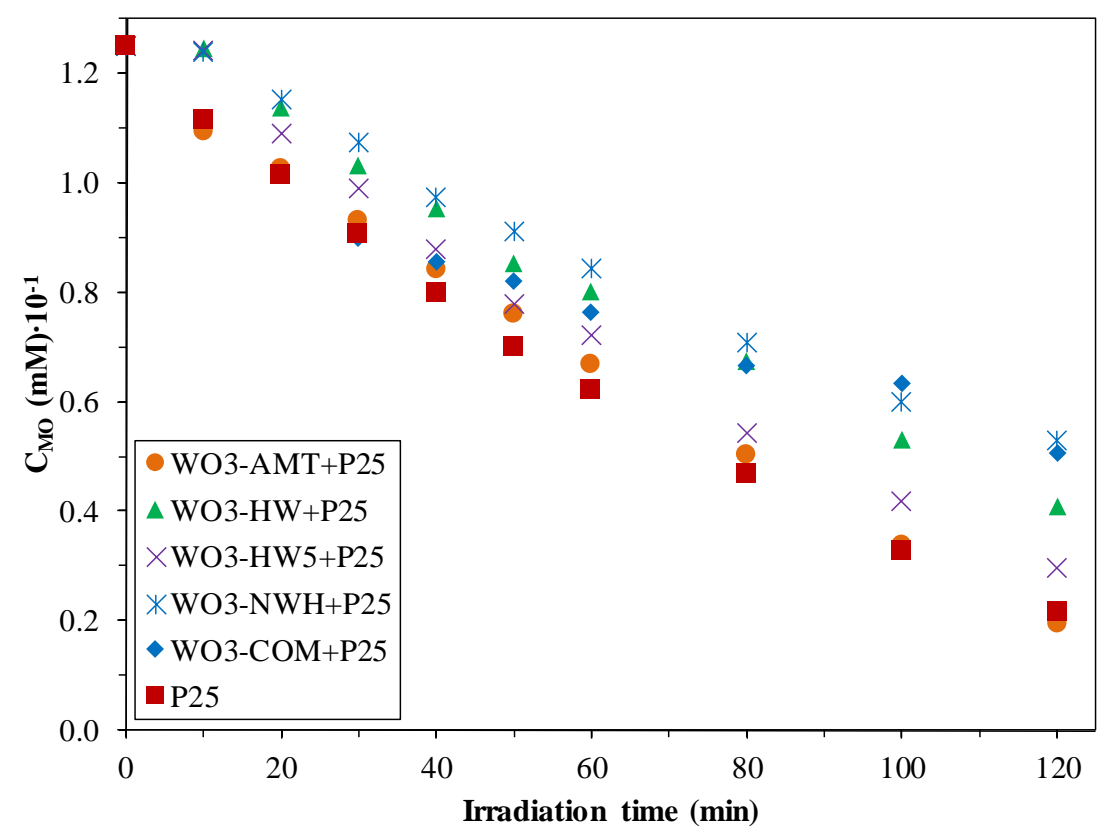

Figure 4. Degradation curves of methyl-orange using $\mathrm{WO}_{3}-\mathrm{P} 25$ composites under UV light, after $2 \mathrm{~h}$.

\section{Discussions of the Photocatalytic Activity Results in the Frame of the Structural and Morphological Features}

\subsection{Morphological Aspects of the Obtained $\mathrm{WO}_{3}$ Microcrystals}

The morphology of the $\mathrm{WO}_{3}\left(\mathrm{WO}_{3}-\mathrm{HW} ; \mathrm{WO}_{3}-\mathrm{HW} 5\right)$ crystals synthesized from tungstic acid was rod-like, accompanied sometimes by nanosheets (Figure 5 ). The crystal size was $\approx 1 \mu \mathrm{m}$, which were built from very small polycrystalline nanoparticles with $d \approx 20 \mathrm{~nm}$. This material "construction" 
was also observed by Liang Zhou and coworkers [20]. Using sodium tungstate as the precursor, the morphology of the tungsten trioxide $\left(\mathrm{WO}_{3}-\mathrm{NWH}\right)$ crystals were fiber-like [21]. Their individual length was $\approx 3-4 \mu \mathrm{m}$. Taking a closer look, it was observed that these fibers were, in fact, fiber bundles ("built" from $\approx 12-14$ smaller nanofibers) composed from much smaller $d=40-50$ nm fibers. Finally, the morphology of the microcrystals $\left(\mathrm{WO}_{3}-\mathrm{AMT}\right)$ obtained from ammonium metatungstate (AMT) was star-like [1]. These stars' mean diameter was $\approx 3-4 \mu \mathrm{m}$ and were composed from microfibers of $\approx 3-4 \mu \mathrm{m}$ length. These were built from several smaller nanowires with a diameter $=10-15 \mathrm{~nm}$ (Figure 5).

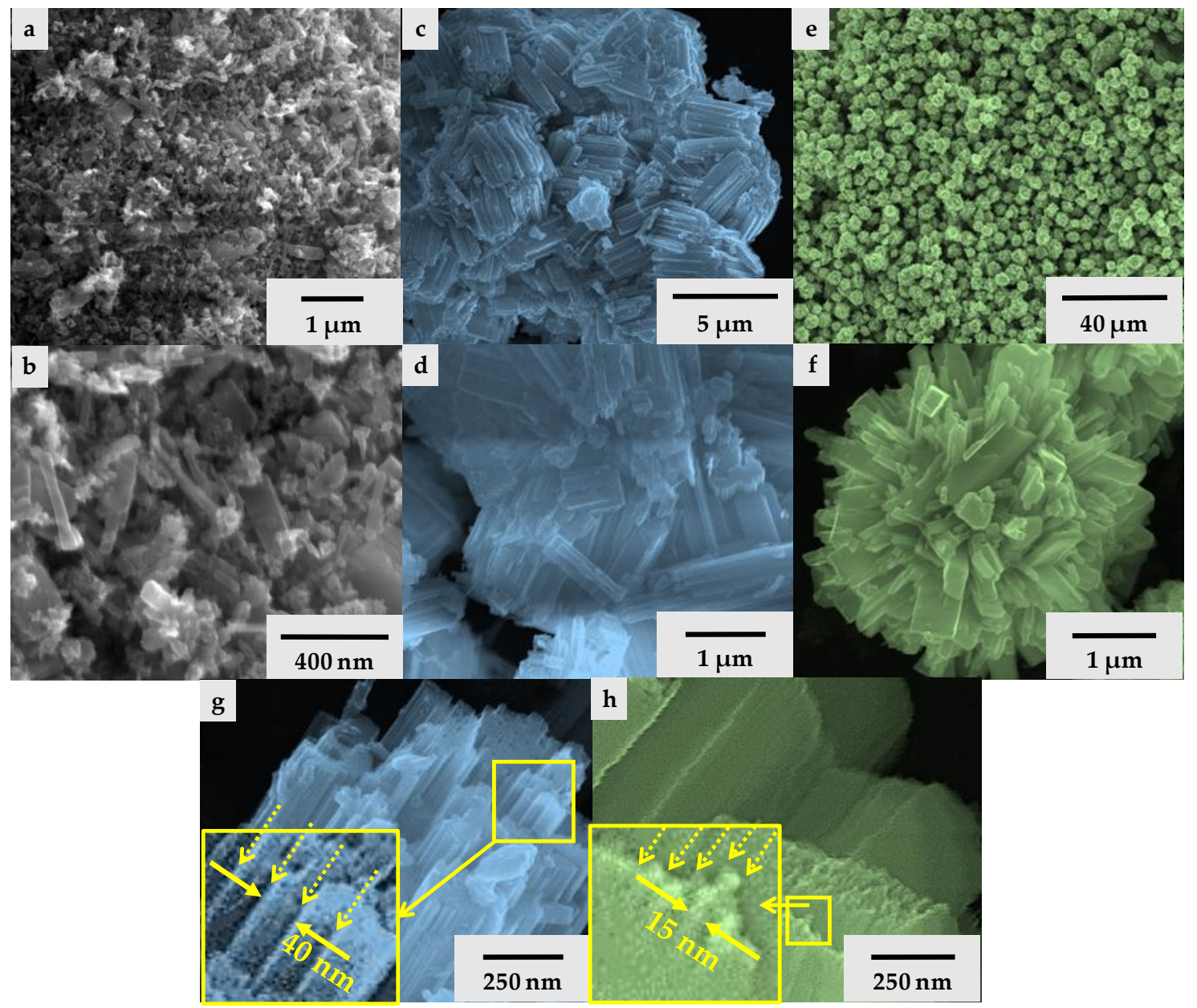

Figure 5. SEM micrographs of $\mathrm{WO}_{3}-\mathrm{HW}, \mathrm{WO}_{3}-\mathrm{HW} 5(\mathbf{a} ; \mathbf{b}) ; \mathrm{WO}_{3}-\mathrm{NWH}(\mathbf{c} ; \mathbf{d} ; \mathbf{g}) ;$ and $\mathrm{WO}_{3}-\mathrm{AMT}$ $(\mathbf{e} ; \mathbf{f} ; \mathbf{h})$ - the yellow dotted arrows are marking the wire boundaries.

\subsection{Crystalline Structure of the Shape-Tailored $\mathrm{WO}_{3}$}

From the XRD patterns, the crystal phase composition and crystal size of the $\mathrm{WO}_{3}$ nanocrystals were evaluated. $\mathrm{WO}_{3}-\mathrm{COM}$ and $\mathrm{WO}_{3}-\mathrm{AMT}$ contained only the monoclinic crystal phase, while $\mathrm{WO}_{3}-\mathrm{NWH}$ contained exclusively $\mathrm{WO}_{3} \cdot 0.33 \mathrm{H}_{2} \mathrm{O}$ hexagonal partial hydrate. Interestingly, $\mathrm{WO}_{3}-\mathrm{HW}$ and $\mathrm{WO}_{3}-\mathrm{HW} 5$ semiconductors contained both of the previously mentioned crystal phases in different amounts (Figure 6, Table 1). The crystal size values determined from the XRD patterns were well-correlated with the observations made in the previous section of the paper (except for the $\mathrm{WO}_{3}-\mathrm{COM}$, which was not shown separately; the determined crystal size was $20 \mathrm{~nm}$ ). More precisely, in the case of the hierarchically structured materials (stars made from thin wires, $\mathrm{WO}_{3}$-AMT and wire bundles made from smaller wires, $\left.\mathrm{WO}_{3}-\mathrm{NWH}\right)$, the small fibers' diameter values determined by XRD (55 nm, $\mathrm{WO}_{3}-\mathrm{NWH} ; 30-35 \mathrm{~nm}, \mathrm{WO}_{3}-\mathrm{AMT}$ ) were in the same range as the ones determined by SEM 
(40-50 nm, $\left.\mathrm{WO}_{3}-\mathrm{NWH} ; 10-15 \mathrm{~nm}, \mathrm{WO}_{3}-\mathrm{AMT}\right)$. The differences in the values can be attributed to the fibers' asymmetrical nature (length/diameter ratio is extremely high-10-15 nm vs. 2-3 $\mu \mathrm{m}$ in sample $\left.\mathrm{WO}_{3}-\mathrm{AMT}\right)$. Another important aspect was noticed when $\mathrm{WO}_{3}-\mathrm{HW}$ and $\mathrm{WO}_{3}-\mathrm{HW}_{5}$ was compared. If the $\mathrm{H}_{2} \mathrm{O}_{2}$ amount was high $\left(\mathrm{WO}_{3}-\mathrm{HW}\right)$, the monoclinic phase was present in $9.6 \mathrm{wt}$ \%, while the hexagonal hydrate was $90.3 \mathrm{wt}$ \%. When the $\mathrm{H}_{2} \mathrm{O}_{2}$ content was lowered, the hexagonal hydrate was still the dominant crystal phase of the powders with a more pronounced content of monoclinic $\mathrm{WO}_{3}$ : 63.6 wt.\% vs. 36.3 wt.\% (monoclinic $\mathrm{WO}_{3}$ ).

It is known that the monoclinic crystal phase of $\mathrm{WO}_{3}$ is very stable, and it is thermodynamically favored if no chemical "constraints" (e.g., shaping agents) are present during the crystallization procedure. If a partial hydrate, such as $\mathrm{WO}_{3} \cdot 0.33 \mathrm{H}_{2} \mathrm{O}$, is desired, then a high ionic strength medium is required, where the ionic strength is determined by a joint cation and foreign anion (e.g., $\mathrm{Na}^{+} / \mathrm{Cl}^{-}$ $\mathrm{Na}_{2} \mathrm{WO}_{4}$ - precursor $/ \mathrm{NaCl}$ ionic strength modifier). These strategies were proven to be efficient, as it was shown in Figure 6 and Table 1. However, to modify the ratio of these two crystal phases, a more elaborate method is required, such as the intermediate peroxo-complex approach, which yields a different ratio of the two crystal phases depending on the $\mathrm{H}_{2} \mathrm{O}_{2}$ content, and it was also proven to be successful. Therefore, the next step is to verify if this crystal phase/morphology changes are related to the materials' optical properties (band-gap value).

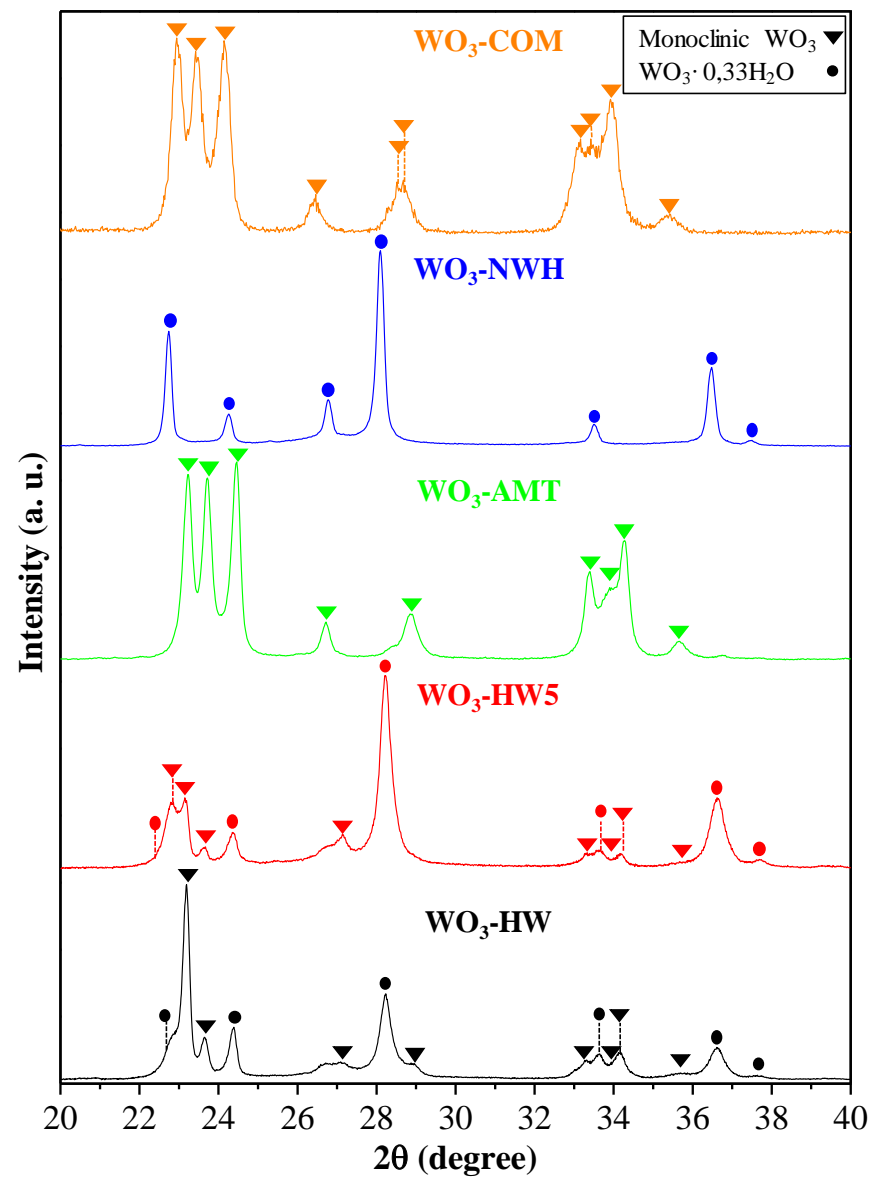

Figure 6. XRD patterns of the obtained $\mathrm{WO}_{3}$.

\subsection{Optical Properties of the Individual $\mathrm{WO}_{3}$ and Composites}

The band-gap value estimated using the light absorption threshold was $450 \mathrm{~nm}(2.75 \mathrm{eV})$ for $\mathrm{WO}_{3}-\mathrm{HW}, 460 \mathrm{~nm}(2.69 \mathrm{eV})$ for $\mathrm{WO}_{3}-\mathrm{NWH}, 475 \mathrm{~nm}(2.61 \mathrm{eV})$ for $\mathrm{WO}_{3}-\mathrm{COM}$, and $550 \mathrm{~nm}(2.25 \mathrm{eV})$ for $\mathrm{WO}_{3}-\mathrm{AMT}$. The lowest band-gap energy was estimated for $\mathrm{WO}_{3}-\mathrm{AMT}$ (interestingly, there was a break 
in the light absorption threshold of this material, which may require additional experimental work to be explained) and $\mathrm{WO}_{3}-\mathrm{COM}$, both of them containing only the monoclinic polymorph of $\mathrm{WO}_{3}$. This was followed by the pure hexagonal partial hydrate containing $\mathrm{WO}_{3}-\mathrm{NWH}$, and, finally by the $\mathrm{WO}_{3}-\mathrm{HW}$ and HW5, which contained both of the previously mentioned crystal phases. Figure 7 shows that, as the two phases were simultaneously present, a unique synergistic change was observable in the UV-Vis spectra, marked by an intensive blue shift of $50 \mathrm{~nm}$ (compared to $\mathrm{WO}_{3}-\mathrm{NWH}$ ) and $100 \mathrm{~nm}$ (compared to $\mathrm{WO}_{3}-\mathrm{AMT}$ ). Furthermore, in $\mathrm{WO}_{3}-\mathrm{HW} 5$, a more significant amount (36.3 wt. \%) of monoclinic $\mathrm{WO}_{3}$ was also evidenced, and it was marked in the spectrum by a small break in the absorption threshold (visible also in the spectrum of $\mathrm{WO}_{3}-\mathrm{AMT}$ ). In the case of the $\mathrm{WO}_{3}-\mathrm{P} 25$ composites, the band-gap values established were further blue shifted, due to the presence of $\mathrm{TiO}_{2}$, although the spectral features of the $\mathrm{WO}_{3}$ were still discernible (Figure 8). The band-gap values were summarized in Table 1.

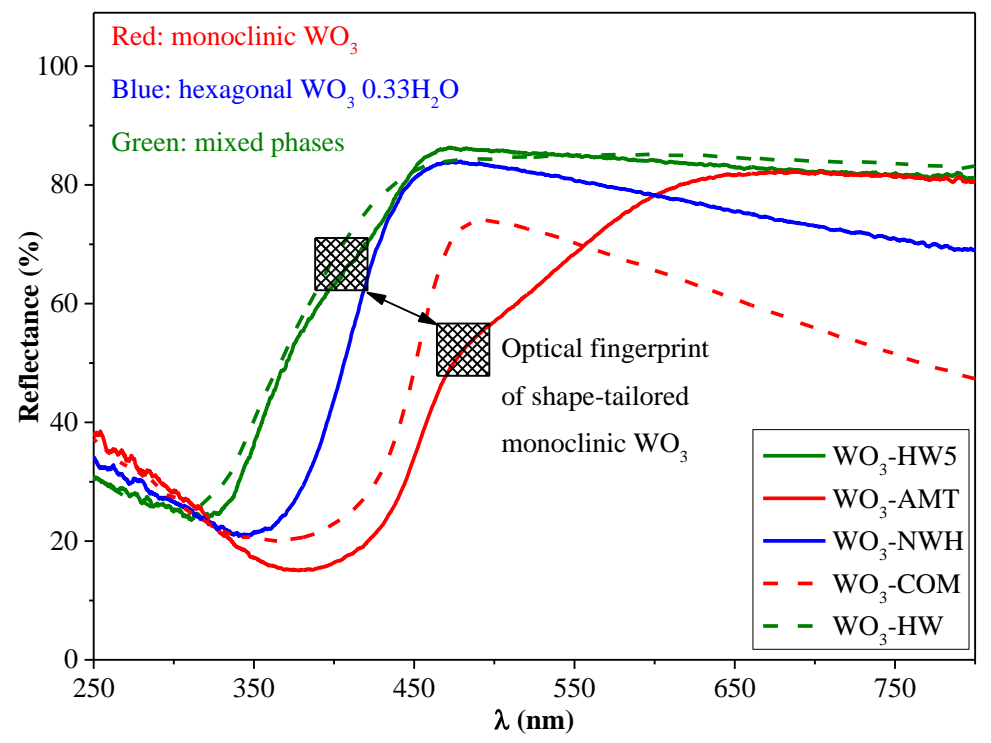

Figure 7. The reflectance spectra of the commercial and synthesized $\mathrm{WO}_{3}$.

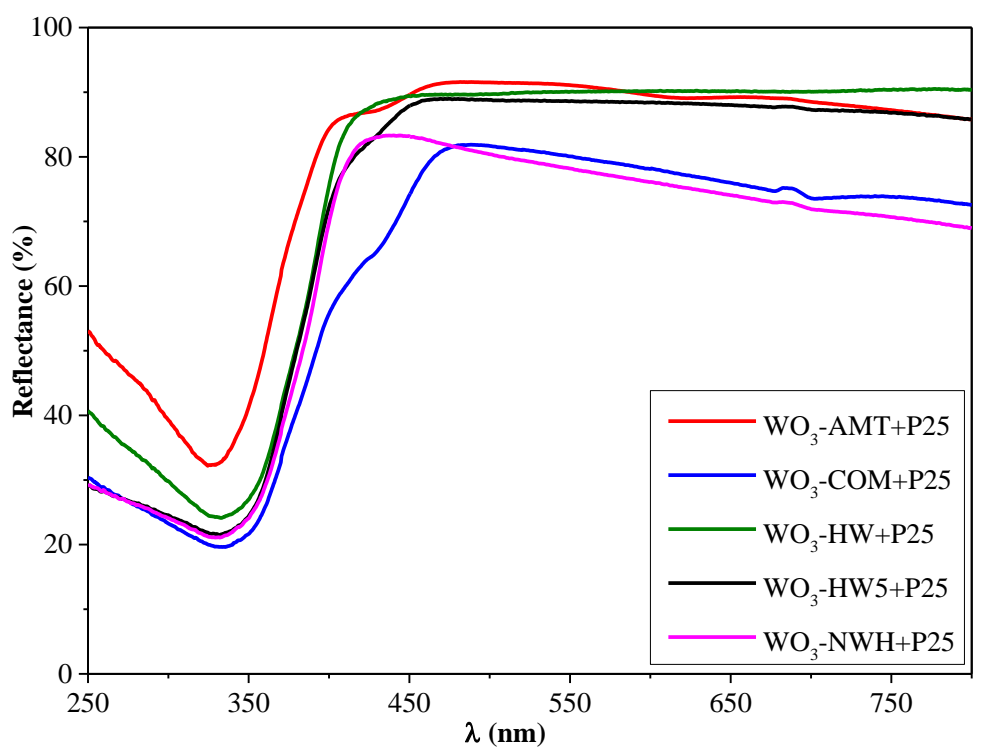

Figure 8. The reflectance spectra of the commercial and synthesized $\mathrm{WO}_{3}-\mathrm{TiO}_{2}$ composites. 
Table 1. The obtained materials' photocatalytic activity and structural properties.

\begin{tabular}{|c|c|c|c|c|c|c|c|}
\hline \multirow{2}{*}{ Sample Name } & \multicolumn{2}{|c|}{ Structure $\mathrm{WO}_{3}$} & \multirow{2}{*}{$\begin{array}{c}\text { Band-gap } \\
(\mathrm{eV})\end{array}$} & \multirow{2}{*}{$\eta_{\text {phenol }}(\%)$} & \multirow{2}{*}{$\begin{array}{c}r_{0, \text { phenol }} \\
\left(\mathrm{mM} \cdot \mathrm{min}^{-1}\right)\end{array}$} & \multirow{2}{*}{$\eta_{\text {MO }}(\%)$} & \multirow{2}{*}{$\begin{array}{c}r_{0, \mathrm{MO}} \\
\left(\mathrm{mM} \cdot \mathrm{min}^{-1}\right)\end{array}$} \\
\hline & ${ }^{*} \mathrm{MC}$ & \#HY & & & & & \\
\hline P25 & - & - & 3.11 & 86.8 & $8.90 \times 10^{-3}$ & 82.8 & 2.26 \\
\hline $\mathrm{WO}_{3}$-HW5 & 36.3 & 63.6 & 2.69 & 0 & - & 0 & - \\
\hline $\mathrm{WO}_{3}-\mathrm{HW}$ & 9.3 & 90.6 & 2.75 & 0 & - & 0 & - \\
\hline $\mathrm{WO}_{3}-\mathrm{NWH}$ & 0 & 100 & 2.69 & 0 & - & 0 & - \\
\hline $\mathrm{WO}_{3}$-AMT & 100 & 0 & 2.25 & 0 & - & 0 & - \\
\hline $\mathrm{WO}_{3}-\mathrm{COM}$ & 100 & 0 & 2.61 & 0 & - & 0 & - \\
\hline $\mathrm{P} 25+\mathrm{WO}_{3}-\mathrm{HW} 5$ & - & - & 3.04 & 66.7 & $8.86 \times 10^{-3}$ & 76.3 & 1.06 \\
\hline $\mathrm{P} 25+\mathrm{WO}_{3}-\mathrm{HW}$ & - & - & 3.00 & 87.2 & $6.53 \times 10^{-3}$ & 67.3 & 1.01 \\
\hline $\mathrm{P} 25+\mathrm{WO}_{3}-\mathrm{NWH}$ & - & - & 2.97 & 44.4 & $5.31 \times 10^{-3}$ & 57.7 & 0.35 \\
\hline $\mathrm{P} 25+\mathrm{WO}_{3}-\mathrm{AMT}$ & - & - & 3.10 & 58.7 & $6.69 \times 10^{-3}$ & 84.6 & 1.66 \\
\hline $\mathrm{P} 25+\mathrm{WO}_{3}-\mathrm{COM}$ & - & - & 2.94 & 49.1 & $11.18 \times 10^{-3}$ & 59.5 & 5.02 \\
\hline
\end{tabular}

${ }^{*} \mathrm{MC}-$ monoclinic $\mathrm{WO}_{3} ; \# \mathrm{HY}-\mathrm{WO}_{3} \cdot 0.33 \mathrm{H}_{2} \mathrm{O}$.

\subsection{The Structure-Morphology-Photocatalytic Activity Relationship}

The correlation between the observed photocatalytic activities and the investigated parameters can be made at three different levels, each of them suggesting new investigation pathways concerning $\mathrm{WO}_{3}$ containing nanocomposites activity-tuning possibilities.

The first approach, which was already discussed in Section 2.1, was the visible light activity potential and the light absorption properties' relationship (Section 3.3). Although all the bare $\mathrm{WO}_{3}$ showed visible light absorption properties (including the fact that their band-gap values were in the visible light region), no visible light activity was observable, neither in the degradation of phenol nor in the degradation of oxalic acid. Additionally, the composites prepared with P25 were also totally inactive under visible light. This result points out the fact that the $\mathrm{WO}_{3}$ crystals main role was in the charge separation process.

The second level approach considers the relationship between the crystals' structure and the obtained photocatalytic efficiencies. It is already known in the case of $\mathrm{TiO}_{2}$ that the photocatalytic activity is strongly dependent on the crystal phase composition (the famous anatase/rutile ratioperfect synergism of the two crystal phases in P25). Therefore, a similar behavior was expected, if the crystal phase composition of the charge separator composite component (in the present case, $\mathrm{WO}_{3}$ ) was altered. In the case of phenol degradation, a small amount $\left(\approx 9 \mathrm{wt}\right.$. \%) of monoclinic $\mathrm{WO}_{3}$ was sufficient to boost (doubling the efficiency) the activity of $\mathrm{WO}_{3} \cdot 0.33 \mathrm{H}_{2} \mathrm{O}$. If the amount of the monoclinic crystal phase increased further, the activity decreased gradually (Figure 9). The crystal phase composition had a reverse effect when the chosen model pollutant was MO. Pure monoclinic $\mathrm{WO}_{3}$ was the best choice to achieve maximum efficiency, because, with the increase of the $\mathrm{WO}_{3} \cdot 0.33 \mathrm{H}_{2} \mathrm{O}$ content, the activity decreased gradually.

The third level approach lies in the morphological control of the $\mathrm{WO}_{3}$ crystals. The most representative evidence for the efficiency of shape tailoring was shown in Figure 9. $\mathrm{WO}_{3}-\mathrm{COM}+$ P25 showed lower photocatalytic efficiency in every one of the investigated cases (phenol and MO degradation). Both $\mathrm{WO}_{3}-\mathrm{COM}$ and $\mathrm{WO}_{3}$-AMT contained only monoclinic $\mathrm{WO}_{3}$, and their crystal size was in the same range. The main difference was in the fact that $\mathrm{WO}_{3}-\mathrm{AMT}$ contained uniform microstars that were formed from very fine nanowire bundles. This hierarchical build-up makes possible a high efficiency charge transport, which favors the separation of the photogenerated charge carriers. Furthermore, this property is exploitable not just in photocatalysis but also in development of gas sensors. 


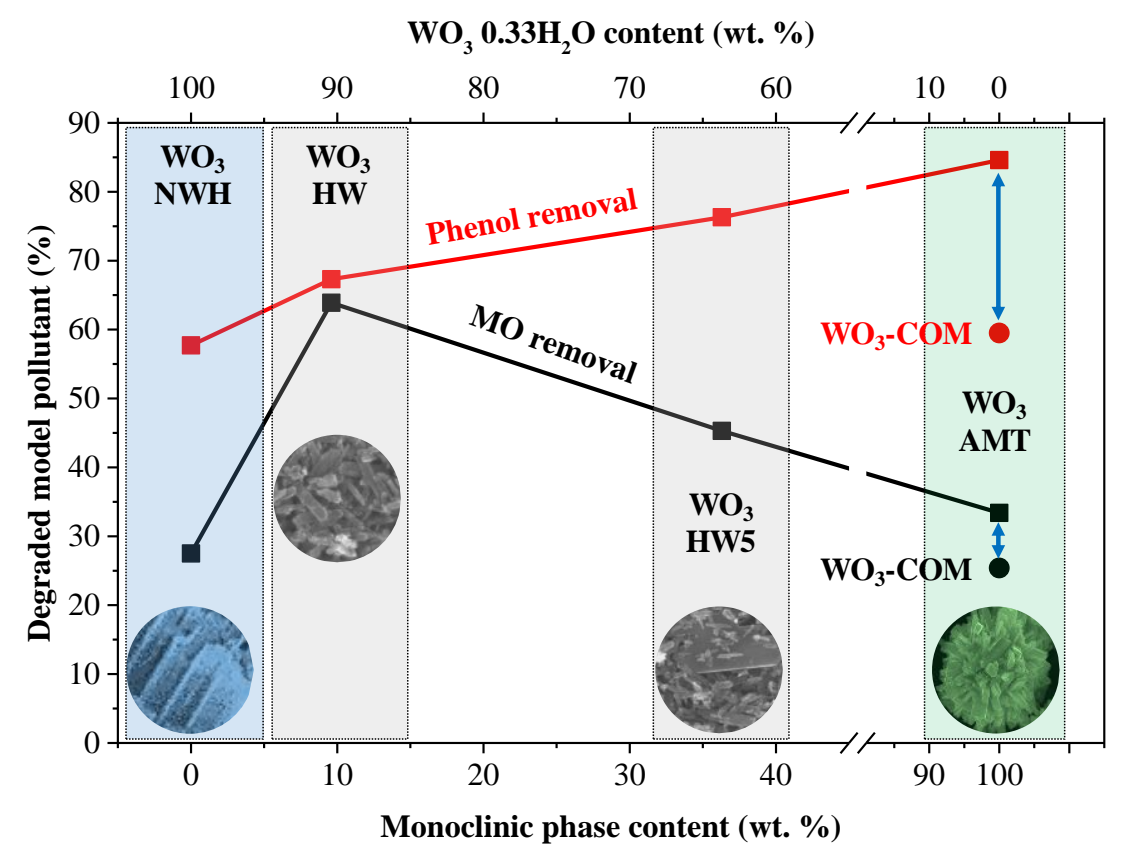

Figure 9. Degradation efficiencies vs. crystal phase composition/morphology.

\section{Materials and Methods}

\subsection{Chemicals}

Tungstic acid $\left(\mathrm{H}_{2} \mathrm{WO}_{4}\right.$, Sigma Aldrich, $\left.99 \%\right)$, sodium tungstate dihydrate $\left(\mathrm{Na}_{2} \mathrm{WO}_{4} \cdot 2 \mathrm{H}_{2} \mathrm{O}\right.$, Sigma Aldrich, 99\%), ammonium metatungstate hydrate (AMT) $\left(\left(\mathrm{NH}_{4}\right)_{6} \mathrm{H}_{2} \mathrm{~W}_{12} \mathrm{O}_{40} \cdot \mathrm{xH}_{2} \mathrm{O}\right.$, Sigma Aldrich, 99.99\%), hydrogen peroxide $\left(\mathrm{H}_{2} \mathrm{O}_{2}\right.$, Sigma Aldrich, 30\%), hydrochloric acid ( $\mathrm{HCl}$, NORDCHIM, 37\%, $12 \mathrm{M})$, sodium chloride ( $\mathrm{NaCl}, \mathrm{NORDCHIM}, 99.5 \%)$ were used as received. For the determination of the photocatalytic activity aqueous solution of phenol $\left(\mathrm{C}_{6} \mathrm{H}_{5} \mathrm{OH}, 99 \%\right.$, Reanal), and oxalic acid $\left(\mathrm{C}_{2} \mathrm{H}_{2} \mathrm{O}_{4}\right.$, Aldrich, $\left.98 \%\right)$ was used.

\subsection{Synthesis of the $\mathrm{WO}_{3}$ Semiconductors}

\subsubsection{Synthesis of $\mathrm{WO}_{3}$ Nanoplates-Intermediate Peroxo-Complex Approach}

For the experiment, $2.5 \mathrm{~g}$ of $\mathrm{H}_{2} \mathrm{WO}_{4}$ was dissolved in a mixture of $30 \mathrm{~mL} 30 \mathrm{wt}$. \% hydrogen peroxide $\left(\mathrm{H}_{2} \mathrm{O}_{2}\right)$ and $10 \mathrm{~mL}$ of distilled water under stirring $(24 \mathrm{~h})$ to form a clear, pale-yellow solution [20]. $2.5 \mathrm{~g}$ of $\mathrm{H}_{2} \mathrm{WO}_{4}$ was dissolved in a mixture of $20 \mathrm{~mL} 30 \mathrm{wt}$. \% hydrogen peroxide $\left(\mathrm{H}_{2} \mathrm{O}_{2}\right)$ and $20 \mathrm{~mL}$ of distilled water under stirring $(24 \mathrm{~h})$ to form a clear/colorless solution. Then, both of the solutions were hydrothermally treated at $180^{\circ} \mathrm{C}$ for $24 \mathrm{~h}$, and a white colloidal suspension was obtained. The products were collected and washed by centrifugation for $3 \times 10 \mathrm{~min}$ at $5000 \mathrm{rpm}$, with distilled water. The washed precipitate was dried at $40{ }^{\circ} \mathrm{C}$ for $24 \mathrm{~h}$. The nanocrystallites synthesized from tungstic acid were named $\mathrm{WO}_{3}-\mathrm{HW}$ and $\mathrm{WO}_{3}-\mathrm{HW}$. The $\mathrm{HW}$ abbreviation comes from the tungstic acid's molecular formula $\mathrm{H}_{2} \mathrm{WO}_{4}$.

\subsubsection{Synthesis of $\mathrm{WO}_{3}$-High Ionic Strength Approach}

For this part of the experiment, $3.29 \mathrm{~g}$ of $\mathrm{Na}_{2} \mathrm{WO}_{4} \cdot 2 \mathrm{H}_{2} \mathrm{O}$ and $1.16 \mathrm{~g}$ of $\mathrm{NaCl}$ were dissolved in $75 \mathrm{~mL}$ distilled water under stirring. The $\mathrm{pH}$ of the suspension was adjusted to 2 with $3 \mathrm{M} \mathrm{HCl}$ aqueous solution. The suspension was stirred at room temperature for $24 \mathrm{~h}$. Then, the mixture was hydrothermally treated at $180{ }^{\circ} \mathrm{C}$ for $24 \mathrm{~h}$, and a green precipitate was finally obtained. The obtained product was collected and washed by centrifugation: for $3 \times 10 \mathrm{~min}$ at $5000 \mathrm{rpm}$ with distilled water. 
After centrifugation, the product was dried at $40{ }^{\circ} \mathrm{C}$ for $24 \mathrm{~h}$ [21]. The sample obtained from sodium tungstate dihydrate was named $\mathrm{WO}_{3}-\mathrm{NWH}$. The $\mathrm{NWH}$ abbreviation comes from the sodium tungstate dihydrate molecular formula $\mathrm{Na}_{2} \mathrm{WO}_{4} \cdot 2 \mathrm{H}_{2} \mathrm{O}$.

\subsubsection{Synthesis of $\mathrm{WO}_{3}$ Nanostars-Low Mobility Anion Approach}

For this part of the experiment, $0.77 \mathrm{~g}$ AMT and $0.53 \mathrm{~mL} \mathrm{HCl}$ was dissolved in $12.5 \mathrm{~mL}$ of distilled water. The solution was stirred for $15 \mathrm{~min}$, then hydrothermally treated at $180{ }^{\circ} \mathrm{C}$ for $4 \mathrm{~h}$, and a yellow colloidal suspension was obtained. The product was collected and washed by centrifugation at $1600 \mathrm{rpm}$ for $15 \mathrm{~min}$ with distilled water. After centrifugation, the precipitate was dried for $6 \mathrm{~h}$ at $70{ }^{\circ} \mathrm{C}$. Finally, the as-obtained powders were thermally treated at $500{ }^{\circ} \mathrm{C}$ for $30 \mathrm{~min}$ [1]. The catalyst obtained using ammonium metatungstate hydrate was named $\mathrm{WO}_{3}$-AMT. The AMT abbreviation originates from the ammonium metatungstate hydrate.

\subsection{Synthesis of the $\mathrm{WO}_{3} / \mathrm{TiO}_{2}$ Nanocomposites}

In this case, the shape controlled $\mathrm{WO}_{3}$ nanocrystallites and Evonik Aeroxide P25 (Manufacturer, City, Country) were used for the preparation of the nanocomposites. In each case, a specific ratio was established between the composite components, according to our recent work: $24 \% \mathrm{WO}_{3}$ and $76 \%$ $\mathrm{TiO}_{2}$ (Evonik Aeroxide P25). The nanocomposites were prepared via mechanical mixing in an agate mortar for $3 \times 5 \mathrm{~min}$ [6] and were named as follows: $\mathrm{WO}_{3}$ name $+\mathrm{P} 25$. The Evonik Aeroxide $\mathrm{TiO}_{2}$ will be referred to as P25 later on, while the commercial $\mathrm{WO}_{3}$ will be denoted as $\mathrm{WO}_{3}-\mathrm{COM}$. The commercial tungsten trioxide was used as a reference due to its property that it was not synthesized via hydrothermal treatment, and it doesn't contain shape tailored $\mathrm{WO}_{3}$ nano and microcrystals.

\subsection{Methods and Instrumentation}

\section{Characterization Methods}

The XRD patterns were recorded on a Shimadzu 6000 diffractometer (Shimadzu Corporation, Kyoto, Japan), using Cu-K $\alpha$ irradiation, $(\lambda=1.5406 \AA)$, equipped with a graphite monochromator. The crystal phase of the tungsten trioxide was evaluated and the crystallites' average size was calculated using the Scherer equation [36].

For measuring the DRS spectra of the samples, a JASCO-V650 spectrophotometer (Jasco Inc., Easton, MD, USA) with an integration sphere (ILV-724) (Jasco Inc., Easton, MD, USA) was used $(\lambda=250-800 \mathrm{~nm})$. The band gap was determined according to references $[34,35,37,38]$.

SEM micrographs were obtained with a FEI Quanta 3D FEG Scanning Electron Microscope (FEI Inc., Dawson Creek, Canada), operating at an accelerating voltage of $25 \mathrm{kV}$.

The photocatalytic tests were performed under UV irradiation in a photoreactor (homemade) ( $1 \mathrm{~g} \cdot \mathrm{L}^{-1}$ suspension concentration, continuous air flow, continuous stirring. $6 \mathrm{~W} \times 6 \mathrm{~W}$ UV fluorescent lamps, $\lambda_{\max }=365 \mathrm{~nm}$, thermostated at $\left.25^{\circ} \mathrm{C}\right)$ under visible irradiation in a photoreactor $\left(1 \mathrm{~g} \cdot \mathrm{L}^{-1}\right.$ suspension concentration, continuous air flow, continuous stirring. $4 \mathrm{~W} \times 24 \mathrm{~W}$ fluorescent lamps, $\lambda>400 \mathrm{~nm}$, thermostated at $25^{\circ} \mathrm{C}$ ) [18]. The suspension containing the photocatalyst and the pollutant (initial concentration of phenol $C_{0 \text {, phenol }}=0.5 \mathrm{mM}$ or oxalic acid $C_{0 \text {, oxalic acid }}=5 \mathrm{mM}$ of methyl orange $(\mathrm{MO}) C_{0, \mathrm{MO}}=125 \mu \mathrm{M}$; catalyst concentration $C_{\text {photocatalyst }}=1 \mathrm{~g} \cdot \mathrm{L}^{-1}$; total volume of the suspension $V_{\text {susp }}=100 \mathrm{~mL}$ ) was continuously purged with air, assuring a constant dissolved oxygen concentration during the whole experiment. The chosen compounds are stable under UV-A, not showing any sign of photolytic (in the absence of the photocatalyst) degradation [37].

Prior to the degradation experiments, the used suspension was kept in the dark for $10 \mathrm{~min}$ to establish the adsorption/desorption equilibrium. For the calculation of the reaction rates, only the first five measurement points (where the influence of the degradation intermediates was insignificant) were considered, applying a pseudo-first order kinetic approach. The error of the photocatalytic degradation 
experiments was verified by 3 degradation experiments with the same catalyst. The maximum error (in the conversion and reaction rate values) was determined to be $\pm 2.5 \%$.

The concentration decrease of the chosen organic substrate (oxalic acid, phenol) was followed using an Agilent 1100 series HPLC system (Agilent Technologies, Santa Clara, CA, USA). The eluent in the case of oxalic acid was a $0.06 \%$ aqueous solution of sulfuric acid, with a $0.8 \mathrm{~mL} \cdot \mathrm{min}^{-1}$ flow rate, the column was Grom Resin ZH (Dr. Maisch HPLC GmbH, Ammerbuch-Entringen, Germany). In the case of phenol, the eluent was a mixture of methanol and water in 7:13 ratio, while using a BST Nucleosyl C-18 column $(4 \mathrm{~mm} \times 250 \mathrm{~mm})$ (Merck, Kenilworth, NJ, USA). The detection wavelengths were the following: in the case of oxalic acid $206 \mathrm{~nm}$ and in the case of phenol $210 \mathrm{~nm}$. The concentration of MO was followed using a JASCO V-650 spectrophotometer at 513 nm (Jasco Inc., Easton, MD, USA).

\section{Conclusions}

The present work showed that the activity of a given nanocomposite $\left(\mathrm{TiO}_{2} / \mathrm{WO}_{3}\right)$ can be tuned by adjusting the structural and morphological properties of the charge separator component (in the present case, $\mathrm{WO}_{3}$ ). The structural fine-tuning was efficient if the crystal phase composition was varied. This resulted in different levels of affinity towards different types of model pollutants (phenol and methyl orange). The controlled shape manipulation was also a viable alternative to enhance the photocatalytic activity, which was proven by the comparison of commercial $\mathrm{WO}_{3}$ and shape-tailored $\mathrm{WO}_{3}$ containing the same crystal polymorph and having a similar crystal size. Although there are still questions unanswered in the present research, it is clear that there is huge potential in the photocatalytic activity enhancement by applying the approaches investigated in this work.

Acknowledgments: The authors wish to thank to the Romanian National Authority for Scientific Research, CNCS-UEFISCDI, project number PN-II-ID-PCE-2011-3-0442. István Székely acknowledges the funding provided by scholarship "Bursă de Performanță Științifică" provided by the Babeș-Bolyai University. In addition, the authors would like to thank Alexandra Csavdári for her help concerning the evaluation of the reaction rates and to Adriana Vulpoi for the SEM micrographs.

Author Contributions: István Székely performed the synthesis of the nanomaterials, and $80 \%$ of the other experimental work, and he also participated in the preparation of the manuscript; Gábor Kovács was the supervisor of the whole experimental work and contributed to the preparation of the manuscript; Lucian Baia's main role was in the data interpretation; Virginia Danciu contributed significantly to the improvement of the manuscript and provided the necessary scientific advising. Zsolt Pap played an important role in the preparation of the manuscript as the corresponding author.

Conflicts of Interest: The authors declare no conflict of interest.

\section{References}

1. Biswas, S.K.; Baeg, J.O. A facile one-step synthesis of single crystalline hierarchical $\mathrm{WO}_{3}$ with enhanced activity for photoelectrochemical solar water oxidation. Int. J. Hydrog. Energy 2013, 8, 3177-3188. [CrossRef]

2. Hoel, A.; Reyes, L.F.; Heszler, P.; Lantto, V.; Granqvist, C.G. Nanomaterials for environmental applications: Novel $\mathrm{WO}_{3}$-based gas sensors made by advanced gas deposition. Curr. Appl. Phys. 2004, 4, 547-553. [CrossRef]

3. Tripathi, A.; Tripathi, V.; Pandey, N.K.; Tiwari, K. Resistive Type Moisture Sensor based on $\mathrm{WO}_{3}$. Nanomat. Sens. Transduc. J. 2012, 143, 152-161.

4. Dickerson, J.H.; Boccaccini, A.R. Electrophoretic Deposition of Nanomaterials; Springer: New York, NY, USA, 2011.

5. Lassner, E.; Schubert, W.D. Tungsten: Properties, Chemistry, Technology of the Element, Alloys, and Chemical Compounds; Kluwer Academic: New York, NY, USA, 1999.

6. Karácsonyi, É.; Baia, L.; Dombi, A.; Danciu, V.; Mogyorósi, K.; Pop, L.C.; Kovács, G.; Coșoveanu, V.; Vulpoi, A.; Simon, S.; et al. The photocatalytic activity of $\mathrm{TiO}_{2} / \mathrm{WO}_{3} /$ noble metal (Au or Pt) nanoarchitectures obtained by selective photodeposition. Catal. Today 2013, 208, 19-27. [CrossRef]

7. Riboni, F.; Bettini, L.G.; Bahnemann, D.W.; Selli, E. $\mathrm{WO}_{3}-\mathrm{TiO}_{2}$ vs. $\mathrm{TiO}_{2}$ photocatalysts: Effect of the $\mathrm{W}$ precursor and amount on the photocatalytic activity of mixed oxides. Catal. Today 2013, 209, 28-34. [CrossRef] 
8. Lee, W.J.; Fang, Y.K.; Ho, J.J.; Hsieh, W.T.; Ting, S.F.; Huang, D.; Fang, H.C. Effects of surface porosity on tungsten trioxide $\left(\mathrm{WO}_{3}\right)$ films' electrochromic performance. J. Electron. Mater. 2000, 29, 29-183. [CrossRef]

9. Shi, F.; Liu, J.X.; Huang, X.; Yu, L.; Liu, S.H.; Feng, X.; Wang, X.K.; Shao, G.L.; Hu, S.C.; Yang, B.; et al. Hydrothermal synthesis of mesoporous $\mathrm{WO}_{3}-\mathrm{TiO}_{2}$ powders with enhanced photocatalytic activity. Adv. Powder Technol. 2015, 26, 1435-1441. [CrossRef]

10. Tennakone, K.; Ileperuma, O.A.; Bandara, J.M.S.; Kiridena, W.C.B. $\mathrm{TiO}_{2}$ and $\mathrm{WO}_{3}$ semiconductor particles in contact: Photochemical reduction of $\mathrm{WO}_{3}$ to the non-stoichiometric blue form. Semicond. Sci. Technol. 1992, 7, 423-424. [CrossRef]

11. Ke, D.; Liu, H.; Peng, T.; Liu, X.; Dai, K. Preparation and photocatalytic activity of $\mathrm{WO}_{3} / \mathrm{TiO}_{2}$ nanocomposite particles. Mater. Lett. 2008, 62, 447-450. [CrossRef]

12. Kim, J.; Bondarchuk, O.; Kay, B.D.; White, J.M.; Dohnálek, Z. Preparation and characterization of monodispersed $\mathrm{WO}_{3}$ nanoclusters on $\mathrm{TiO}_{2}$ (110). Catal. Today 2007, 120, 186-195. [CrossRef]

13. Al-Kandari, H.; Al-Kharafi, F.; Al-Awadi, N.; El-Dusouqui, O.M.; Katrib, A. Surface electronic structure-catalytic activity relationship of partially reduced $\mathrm{WO}_{3}$ bulk or deposited on $\mathrm{TiO}_{2}$. J. Electron. Spectrosc. 2006, 151, 128-134. [CrossRef]

14. Williams, D.E.; Aliwell, S.R.; Pratt, K.F.E.; Caruana, D.J.; Jones, R.L.; Cox, R.A.; Hansford, G.M. Modeling the response of a tungsten oxide semiconductor as a gas sensor for the measurement of ozone. Meas. Sci. Technol. 2002, 13, 923-931. [CrossRef]

15. Zhang, H.; Liu, Z.; Yang, J.; Guo, W.; Zhu, L.; Zheng, W. Temperature and acidity effects on $\mathrm{WO}_{3}$ nanostructures and gas-sensing properties of $\mathrm{WO}_{3}$ nanoplates. Mater. Res. Bull. 2014, 57, 260-267. [CrossRef]

16. Baia, L.; Orbán, E.; Fodor, S.; Hampel, B.; Kedves, E.Z.; Saszet, K.; Székely, I.; Karácsonyi, É.; Réti, B.; Berki, P.; et al. Preparation of $\mathrm{TiO}_{2} / \mathrm{WO}_{3}$ composite photocatalysts by the adjustment of the semiconductors' surface charge. Mater. Sci. Semicond. Proc. 2016, 42, 66-71. [CrossRef]

17. Wang, X.; Zhang, H.; Liu, L.; Li, W.; Cao, P. Controlled morphologies and growth direction of $\mathrm{WO}_{3}$ nanostructures hydrothermally synthesized with citric acid. Mater. Lett. 2014, 130, 248-251. [CrossRef]

18. Sungpanich, J.; Thongtem, T.; Thongtem, S. Photocatalysis of $\mathrm{WO}_{3}$ nanoplates synthesized by conventional hydrothermal and microwave-hydrothermal methods and of commercial $\mathrm{WO}_{3}$ nanorods. J. Nanomater. 2014, 2014, 1-8. [CrossRef]

19. Adhikari, S.; Sarkar, D. High Efficient Electrochromic $\mathrm{WO}_{3}$ Nanofibers. Electrochim. Acta 2014, 138, $115-123$. [CrossRef]

20. Zhou, L.; Zou, J.; Yu, M.; Lu, P.; Wei, J.; Qian, Y.; Wang, Y.; Yu, C. Green Synthesis of Hexagonal-Shaped $\mathrm{WO}_{3} \cdot 0.33 \mathrm{H}_{2} \mathrm{O}$ Nanodiscs, Composed of Nanosheets. Cryst. Growth Des. 2008, 8, 3993-3998. [CrossRef]

21. Liu, X.; Zhang, J.; Yang, T.; Guo, X.; Wu, S. Synthesis of Pt nanoparticles functionalized $\mathrm{WO}_{3}$ nanorods and their gas sensing properties. Sens. Actuators B 2011, 156, 918-923. [CrossRef]

22. Ohtani, B.; Prieto-Mahaney, O.O.; Li, D.; Abe, R. What is Degussa (Evonik) P25? Crystalline composition analysis, reconstruction from isolated pure particles and photocatalytic activity test. J. Photochem. Photobiol. A 2010, 216, 179-182. [CrossRef]

23. Veréb, G.; Ambrus, Z.; Pap, Z.; Kmetykó, Á.; Dombi, A.; Danciu, V.; Cheesman, A.; Mogyorósi, K. Comparative study on UV and visible light sensitive bare and doped titanium dioxide photocatalysts for the decomposition of environmental pollutants in water. Appl. Catal. A 2012, 417-418, 26-36. [CrossRef]

24. Kovács, G.; Fodor, S.; Vulpoi, A.; Schrantz, K.; Dombi, A.; Hernádi, K.; Danciu, V.; Pap, Z.; Baia, L. Polyhedral $\mathrm{Pt}$ vs. spherical Pt nanoparticles on commercial titanias: Is shape tailoring a guarantee of achieving high activity? J. Catal. 2015, 325, 156-167. [CrossRef]

25. Ryu, J.; Choi, W. Substrate-specific photocatalytic activities of $\mathrm{TiO}_{2}$ and multiactivity test for water treatment application. Environ. Sci. Technol. 2008, 42, 294-300. [CrossRef] [PubMed]

26. Bai, S.; Liu, H.; Sun, J.; Tian, Y.; Chen, S.; Song, J.; Luo, R.; Li, D.; Chen, A.; Liu, C. Improvement of $\mathrm{TiO}_{2}$ photocatalytic properties under visible light by $\mathrm{WO}_{3} / \mathrm{TiO}_{2}$ and $\mathrm{MoO}_{3} / \mathrm{TiO}_{2}$ composites. Appl. Surf. Sci. 2015, 338, 61-68. [CrossRef]

27. Liu, S.; Huang, J.; Cao, L.; Li, J.; Ouyang, H.; Tao, X.; Liu, C. One-pot synthesis of $\mathrm{TiO}_{2}-\mathrm{WO}_{3}$ composite nanocrystallites with improved photocatalytic properties under natural sunlight irradiation. Mater. Sci. Semicond. Proc. 2014, 25, 106-111. [CrossRef] 
28. Aslam, M.; Iqbal, M.; Ismail, I.; Chandrasekaran, S.; Hameed, A. Morphology controlled bulk synthesis of disc-shaped $\mathrm{WO}_{3}$ powder and evaluation of its photocatalytic activity for the degradation of phenols. J. Hazard. Mater. 2014, 276, 120-128. [CrossRef] [PubMed]

29. Vamvasakis, I.; Georgaki, I.; Vernardou, D.; Kenanakis, G.; Katsarakis, N. Synthesis of $\mathrm{WO}_{3}$ catalytic powders: Evaluation of photocatalytic activity under NUV/visible light irradiation and alkaline reaction pH. J. Sol-Gel Sci. Technol. 2015, 76, 120-128. [CrossRef]

30. Luo, X.; Deng, F.; Min, L.; Luo, S.; Guo, B.; Zeng, G.; Au, C. Facile one-step synthesis of inorganic-framework molecularly imprinted $\mathrm{TiO}_{2} / \mathrm{WO}_{3}$ nanocomposite and its molecular recognitive photocatalytic degradation of target contaminant. Envir. Sci. Technol. 2013, 47, 737-744.

31. DePuccio, D.P.; Botella, P.; O'Rourke, B.; Landry, C.C. Degradation of Methylene Blue Using Porous $\mathrm{WO}_{3}$, $\mathrm{SiO}_{2}-\mathrm{WO}_{3}$, and Their Au-Loaded Analogs: Adsorption and Photocatalytic Studies. ACS Appl. Mater. Interf. 2015, 7, 1987-1996. [CrossRef] [PubMed]

32. Hu, H.; Deng, C.; Xu, J.; Zheng, Q.; Chen, G.; Ge, X. Facile synthesis of hierarchical $\mathrm{WO}_{3}$ nanocakes displaying the excellent visible light photocatalytic performance. Mater. Lett. 2015, 161, 17-19. [CrossRef]

33. Vajda, K.; Saszet, K.; Kedves, Z.; Kása, Z.; Danciu, V.; Baia, L.; Magyari, K.; Hernádi, K.; Kovács, G.; Pap, Z. Shape-controlled agglomeration of $\mathrm{TiO}_{2}$ nanoparticles New insights on polycrystallinity $v s$. single crystals in photocatalysis. Ceram. Int. 2016, 42, 3077-3087. [CrossRef]

34. Kovács, G.; Baia, L.; Vulpoi, A.; Radu, T.; Karácsonyi, É.; Dombi, A.; Hernádi, K.; Danciu, V.; Simon, S.; Pap, Z $\mathrm{TiO}$ /WO3/Au nanoarchitectures' photocatalytic activity, "from degradation intermediates to catalysts' structural peculiarities", Part I: Aeroxide P25 based composites. Appl. Catal. B. Environ. 2014, 147, 508-517. [CrossRef]

35. Baia, L.; Vulpoi, A.; Radu, T.; Karácsonyi, É.; Dombi, A.; Hernádi, K.; Danciu, V.; Simon, S.; Norén, K.; Canton, S.E.; et al. $\mathrm{TiO}_{2} / \mathrm{WO}_{3} /$ Au nanoarchitectures' photocatalytic activity "from degradation intermediates to catalysts' structural peculiarities" Part II: Aerogel based composites-Fine details by spectroscopic means. Appl. Catal. B 2014, 148-149, 589-600. [CrossRef]

36. Jenkins, R.; Snyder, R.L. Introduction to X-Ray Powder Diffractometry; John Wiley \& Sons: New York, NY, USA, 1996; pp. 1417-1418.

37. Pap, Z.; Danciu, V.; Cegléd, Z.; Kukovecz, Á.; Oszkó, A.; Dombi, A.; Mogyorósi, K. The influence of rapid heat treatment in still air on the photocatalytic activity of titania photocatalysts for phenol and monuron degradation. Appl. Catal. B. Environ. 2011, 101, 461-470. [CrossRef]

38. Kubelka, P.; Munk, F. Ein Beitrag zur Optik der Farbanstriche. Zeits. Phys. 1931, 12, 593-601. 